\title{
HOMENAGEM A EDGAR MORIN: ENTRE O CONHECIMENTO E A VIDA
}

HOMAGE TO EDGAR MORIN: BETWEEN KNOWLEDGE AND LIFE

HOMENAJE A EDGAR MORIN: ENTRE EL CONOCIMIENTO Y LA VIDA

\author{
Maria Lucia Rodrigues \\ Doutora em Serviço Social \\ Pontifícia Universidade Católica - PUC/SP \\ São Paulo - SP - Brasil \\ nemess@ pucsp.br
}

Resumo: O texto pretende alcançar Edgar Morin em seus 100 anos. Remete à sua obra como à de um visionário que sabe explorar genialidade intelectual e experiência vivida. Através de alguns depoimentos de pesquisadores, revela a forte expressão do pensamento complexo em trajetórias profissionais e pessoais. E, no encontro com o autor, a importância da compreensão humana para superar demônios e possessões da razão na formação do pensamento livre.

Palavras-chave: compreensão humana; conhecimento e vida; pensamento complexo.

Abstract: The aim of this text is to mark Edgar Morin's 100th year. It hails his work as that of a visionary who knows how to explore intellectual genius and hands-on experience. A number of researchers provide testimonies which reveal the strong expression of complex thought in professional and personal paths and, in the meeting with the author, the importance of human understanding to overcome demons and possessions of reason in the formation of free thought.

Keywords: human understanding; knowledge and life; complex thinking.

Resumen: El texto pretende alcanzar el pensamiento de Edgar Morin a sus 100 años. Se refiere a su obra como a la de un visionario que sabe explorar genialidad intelectual y experiencia vivida. A través de algunos testimonios de investigadores, revela la fuerte expresión del pensamiento complejo en trayectorias profesionales y personales. Y en el encuentro con el autor, manifiesta la importancia de la comprensión humana para superar demonios y posesiones de la razón en la formación del pensamiento libre.

Palabras clave: comprensión humana; conocimiento y vida; pensamiento complejo.

\section{Para citar - (ABNT NBR 6023:2018)}

RODRIGUES, Maria Lucia. Homenagem a Edgar Morin: entre o conhecimento e a vida. Eccos - Revista Científica, São Paulo, n. 57, p. 1-8, e20268, abr./jun. 2021. Disponível em: https://doi.org/10.5585/eccos.n57.20268. 


\section{Homenagem a Edgar Morin: entre o conhecimento e a vida}

Esperança não é certeza,
traz a consciência dos perigos e das ameaças,
mas nos faz tomar partido e fazer apostas. (MORIN, 2020, p. 94).

Como homenagear o homem Edgar Morin, que fantasticamente chega aos seus cem anos? Alguém como ele não cabe em nenhum modelo. Espírito contestador, com incrível capacidade de "religar" conhecimentos de maneira ágil e abrangente, tantas definições já lhe couberam, fazendo sentido à sua inquietação, curiosidade, alegria e audácia. Morin enfrentou e enfrenta a rigidez acadêmica com seus propósitos interdisciplinares, atravessando, com a habilidade de um alquimista, diferentes áreas do saber, como biologia, matemática, filosofia, sociologia, antropologia, economia, política, ecologia, cibernética, entre outras, o que lhe permitiu construir, como definiu, o "pensamento complexo".

Na densa obra de seis volumes, O Método, publicada entre 1977 e 2004, construiu, organizou e principalmente "ensinou”, com intuições lógicas e uma epistemologia complexa, como conjugar conhecimentos e chegar mais perto de uma compreensão do real. Fortemente tocado pelos mistérios e pelas contradições do humano, além de $O$ Método, contemplou-nos com muitas outras obras (O Homem e a Morte, Diários, Cabeça Bem-Feita, Os Sete Saberes Necessários à Educação do Futuro, Terra-Pátria, A Religação dos Saberes, A Via, etc.), que foram tecendo a grande teia de saberes alimentados com intensas experiências de vida. $\mathrm{O}$ fato de Edgar Morin ter pertencido ao partido comunista francês, integrado a resistência francesa na segunda guerra mundial e vivido invernos em trincheiras, fez desse homem (como poucos outros) um diferente pensador, tornando sua história, neste importante século, a expressão de sua trajetória. Além do aprendizado da sociedade e da história em Marx, em sua formação transitou por Heidegger, Kierkegaard, Scheler, entre tantos outros, mas foi também um boêmio, incorporado às artes, ao cinema e ao teatro, não somente como expressão estética, mas como fonte de conhecimentos.

Não exclusivo nem excludente, Edgar acolhe o imprevisível como condição para alçar o criativo, para conservar a tolerância, manter a esperança e uma racionalidade iluminada. Extremamente inteligente, indisciplinado, amorável, carismático, liberto, sensível e aglutinador, gosta de manter as pessoas em sua volta e tem paciência com elas.

Morin sempre me surpreendeu. Terrivelmente assediado que sempre foi (forte limite para os mais tímidos), recebeu-me em seu convívio de amigos e se tornou, meu mestre. A afinidade com o "pensamento complexo" e o carinho por este mestre se espalham em tempos e 
lugares diversos, entre estudantes, pesquisadores, intelectuais e estudiosos de diferentes áreas de conhecimento. É que neste pensamento há uma espécie de apelo "parresiástico"1, que provoca aqueles que o conhecem a levar a termo suas propostas e nelas projeta um certo estilo, um certo modo de ser e de pensar.

Nesta perspectiva, compartilho alguns testemunhos de estudantes e profissionais que souberam apreender o "pensamento complexo" e nele encontraram um suporte para seus conhecimentos, para sua trajetória pessoal, assim como para a compreensão da vida e das relações humanas.

\section{Testemunhos ${ }^{2}$}

Já havia tido contato com o pensamento de Edgar Morin em muitos textos e em muitas leituras que sempre couberam perfeitamente com o que sentia ou pensava até então. Entretanto, quando conheci a professora Maria Lucia Rodrigues na PUC/São Paulo, esse contato foi mais visceral e, somente assim, pude entender o tamanho do impacto de ter alguém traduzindo seus pensamentos e adentrando na alma daquelas pessoas para ajudálas a encontrar um caminho interno e não se perderem no encontro com o sofrimento do outro.

Quanto a mim, cheguei em silêncio, carregada de isolamento, de anos de prática com pessoas fronteiriças, que anestesiam com álcool e outras drogas suas profundas agonias e desamparo. Pessoas que brincam com a morte e chegam muito perto do abismo. Não sei muito ao certo, mas muitas vezes ou talvez, na maioria das vezes, consigo encostar nessas almas e, em muitos momentos, trazê-las de volta para momentos de alívio sem se entorpecerem. Morin expressou, em pouquíssimas palavras, o meu sentimento de anos acumulados: que estar com essas pessoas é "esperar o inesperado". Sempre sem ter que me perder por isso. Os 100 anos de Morin precisam ser celebrados e coroados pela sua imensa sabedoria e luz. A capacidade de expressar o que vai em seu complexo pensamento é o que nos aproxima da preciosidade do seu conhecimento. Poder ter Morin mais perto significa compreensão da dor humana, é uma benção. (Maria Cristina Greco).

As contribuições do pensamento complexo em minha trajetória se iniciaram em 2007, com a designação da professora Maria Lucia Rodrigues, como orientadora no mestrado da PUC/SP. Conviver com as contradições sem querer aboli-las ou anulá-las fez-me sobreviver no universo acadêmico e, após naturalizá-las, também para além dele, na maternidade e nas demais relações. Não esperar o bem como a única atitude possível fezme participar de pesquisa sobre o sistema prisional feminino e o tráfico, durante o curso de pós-graduação, desnudada de verdades prévias ou julgamentos imprecisos. A compreensão que então tive dos depoimentos de tantas mulheres em situação de cárcere não me seria possível sem a contribuição do pensamento complexo. Presente em todas as propostas da professora Maria Lucia, essa maneira de ler as realidades passou a ser vivenciada também por mim. Isso me permitiu orientar mais de 3 mil jovens na última década, a partir deste olhar cuidadoso. Com o aprofundamento no viver sob a ótica do pensamento complexo, fui assim sendo ensinada a ser educadora. Assim, é com as lembranças de estudante do mestrado que sigo também como mestra, consciente de propagar maneiras de se relacionar com a humanidade latentes na complexidade. (Ana Luiza Biazeto).

\footnotetext{
${ }^{1}$ Conforme Muchail (2011, p. 102), o sentido corrente de "parresia", de modo genérico, significa “[...] franqueza, abertura do coração, do pensamento, da palavra, tudo-dizer, franco-falar, dizer-verdadeiro". Refere-se à antilisonja: "A palavra franca não objetiva a dependência daquele a quem se endereça; muito ao contrário, o discurso verdadeiro, precisamente por ser verdadeiro, prepara sua própria dispensa porque conduz o outro à suficiência e à autonomia” (MUCHAIL, 2011, p. 108).

${ }^{2}$ Os testemunhos foram solicitados livremente a profissionais pesquisadores e/ou ex-alunos da Pós-Graduação em Serviço Social da PUC/SP e de outras áreas.
} 
Meu primeiro contato com a obra de Edgar Morin se deu através dos Sete saberes necessários à educação do futuro, material exigido para o processo seletivo de mestrado. Mas, como a realidade comporta o mistério, me surpreendeu ler sobre a condição humana num livro que falaria sobre educação. Isso me colocou em contato com a complexidade, algo novo em conceito para mim, mas que, de alguma forma, se conectava a alguma parte de mim mesma. E assim ocorreu. As obras de Morin, sua perspectiva deliciosa e libertária me convidava a enxergar a poesia da vida, na possibilidade e fé de que o encontro entre pessoas pode ressignificar existências. A abrangência de seus pensamentos, ao mesmo tempo em que traz o próprio planeta em perspectiva, conecta simultaneamente as partes, as micro partes, as nano partes, integrando-nos a nós mesmos e ao planeta terra. O presente está na ancestralidade. Poder encontrar no serviço social por meio do NEMESS um espaço e um lugar de aprofundamento e de vivência de tantos outros e outras, me levou, certamente, a ampliar meu pensamento e minha prática. A teoria da complexidade e a ideia da racionalidade aberta tornou e torna minha atuação profissional menos radical e determinista, mais tolerante, atenta e paciente aos processos históricos em uma sociedade planetária. (Juliana Fernandes).

O pensamento complexo permitiu ampliar minha visão na profissão e na minha própria vida. Todo o aprendizado que tive através de aulas, leituras e orientações no mestrado produziram grandes mudanças em mim; ampliei meu olhar, passei a considerar os diferentes caminhos, levar em conta os acasos que podem ocorrer no percurso, tentando sempre fazer a diferença, o meu melhor. A partir dos princípios da complexidade, o dialógico, o recursivo e o hologramático, compreendi os desafios do conhecimento: é possível pensar o não pensado, conviver com as diferenças e oposições, tentar dialogar com elas, considerá-las. Entender que não só a parte está no todo, mas que o todo também está na parte propiciou maior compreensão sobre o outro, a natureza, o universo; as interações que mantenho com o outro, com o meio ambiente impactam sobre mim, porque sou parte deles e eles são parte de mim. Entender essa unidade no diverso e o diverso na unidade modifica nosso olhar, nossas ações, nossos pensamentos e os caminhos que vamos seguir. (Paola Cordeiro).

Quando iniciei a pós-graduação no Brasil tive um feliz reencontro com as ideias de Edgar Morin - iniciado na Colômbia, meu país de origem. Fazendo uma revisão no site do programa de doutorado da PUC/SP para escolher um/a orientador/a foi gratificante e surpreendente localizar um grupo de pesquisa $(\mathrm{NEMESS})^{3}$ e uma professora que trabalhava com esta orientação, o pensamento complexo, num curso brasileiro de serviço social reconhecido pelo predomínio do pensamento marxista. Apreciei nesse momento constatar no NEMESS uma espécie de oásis de céu aberto, ao meio do invernadouro da floresta vermelha. Desses tempos, lembro-me apreciar especialmente a ideia da dialogicidade e do princípio do terceiro incluído. A dialogicidade propõe afastar de nossa cabeça a lógica de considerar uma situação apenas a partir do antagonismo entre "ser" e "não ser" para explicar situações sociais; o diálogo é a alternativa à dialética materialista que aspira ao predomínio de uma das partes em antagonismo sobre a outra. $\mathrm{O}$ terceiro incluído, por sua vez, convida para que nosso pensamento se abra para várias possibilidades de realidade e permite dar lugar às explicações imprevistas e, portanto, fora da lógica única do binarismo/antagonismo. A aprendizagem foi dura. O estudo custou, mas o que custou ainda mais foi incorporar na prática a reflexão sobre esses valores compreensivos da realidade. Isso porque é mais fácil e tranquilo ver a realidade como um produto dos contrastes e ver aquilo de que discordo, não partilho e que, portanto, facilmente julgo e "me afasto". Difícil é colocar em prática a própria complexidade do pensamento e na vida aprender a conviver com aquilo que para nós é incompleto, ilógico, irracional. (Ruby Esther de Léon).

${ }^{3}$ Núcleo de Estudos e Pesquisas sobre Ensino e Questões Metodológicas em Serviço Social (NEMESS) do Programa de Estudos Pós-Graduados em Serviço Socia da PUC/SP. 
O pensamento complexo me desafia, me liberta, amplia meus conhecimentos, me conecta e me coloca em movimento. Também traz desconforto e inquietude diante de um mundo que separa, promove fronteiras e de uma ciência que continua disciplinar e fragmentada. Mas, este é um desconforto do qual não prescindo. A complexidade permite uma compreensão profunda da ligação entre todo e partes, entre o homem e a natureza, uma compreensão sobre a natureza e a condição humana, olhando com cuidado os fios que tecem e estão conectados às diferentes realidades da existência humana, da vida, das culturas. Compreender que tudo está conectado deveria ser o grande estímulo para superar as profundas desigualdades que mantemos em nossa sociedade e tentar uma nova forma de civilização com menos fanatismos e intolerâncias. A você e a Morin, minha profunda gratidão por terem, de modo acolhedor e amoroso, oportunizado a ampliação de meus conhecimentos na perspectiva da humanização e de uma ética da responsabilidade. (Andréia Estrella).

Pode-se fazer decorrer destes testemunhos a percepção de que o "pensamento complexo" não é uma teoria fácil para se compreender e também para se viver. Diz Morin (1997, p. 66): “[...] as contradições são inerentes a minha visão, a meu sentimento e a minha concepção de mundo". Há o desafio de levar a termo os conhecimentos subjacentes à complexidade, seus princípios, suas bases filosóficas e epistêmicas que se projetam em um estilo, em atitudes, nos modos de pensar de seus estudiosos; entre compreender e viver a complexidade existe uma longa distância; a virtude está em viver o discurso e a teoria na prática, em estender o conhecimento na ação, incorporando o fato de que a autocrítica é a preparação para a verdadeira consciência e que “[...] nossa necessidade de civilização abrange a necessidade de uma civilização do espírito" (MORIN, 1994, p. 151). Em Le vif du sujet, Morin (2003, p. 169) reflete sobre a conduta humana e nos alerta que,

[...] onde imaginou encontrar uma saída, libertação, virtude que era o meio militante, não foi o que ocorreu: [...] a virtude antiburguesa tinha se erodido no cotidiano ou virado fanatismo, e onde [...] as ideias tinham sugado toda a substância da realidade; assim, socialistas viviam, consagravam-se, sacrificavam-se à ideia de fraternidade, mas tinham se tornado incapazes de uma relação fraterna concreta.

Esse prudente alerta pode fazer toda a diferença no cotidiano de nossas vidas e em todo o contexto de nossas relações sociais.

\section{Em busca de minha própria saída: superando meus próprios demônios}

Todos fazemos escolhas durante nossa trajetória de vida profissional e Morin foi uma escolha intuitiva. Para mim, ele é, sem dúvida, um dos pensadores mais relevantes e provocativos da contemporaneidade.

Quando, por volta de 1980, iniciava-se em minha profissão (Serviço Social) uma dinâmica acadêmica de ruptura com o que se considerou matriz conservadora no âmbito dos conhecimentos que davam suporte à profissão, a PUC/SP foi sede de um movimento forte e 
reflexivo para uma estrutural mudança curricular, que definia a teoria marxista como eixo hegemônico do curso e que viabilizou a elaboração e implantação de um novo projeto éticopolítico, também hegemônico para a profissão. Os docentes na época e os assistentes sociais, de um modo geral, aprimoraram seus conhecimentos, alinhando-se a pensadores como Marx, Engels, Lukács, entre outros, representantes da escola crítica marxista, identificados com uma intervenção radical do Estado para combater as desigualdades sociais produzidas pelo capitalismo. Mesmo reconhecendo a importância e incorporando a teoria de Marx, sentia particularmente outras inquietações e a necessidade de complementar aqueles conhecimentos com outras teorias que ampliassem cada vez mais minha compreensão sobre a condição humana.

Assim, chegou às minhas mãos o livro Para Sair do Século XX, de Edgar Morin, editado no Brasil em 1986, em que realizou análises contundentes e provocativas. Afirmava que, para vermos melhor o mundo, é preciso saber olhar para nós mesmos, não apenas considerarmos as relações das forças econômicas e políticas, mas também o jogo da verdade e do erro; dizia que estávamos na pré-história do espírito humano, na idade de ferro planetária, que era necessário lutar pelo renascimento da humanidade e que existe uma profunda reciprocidade entre a ordem interna do eu e a ordem da sociedade. O desenvolvimento destas ideias foi suficiente para atrair minha atenção, minha curiosidade e motivação. Comecei, então, a aprender o que ele definia por "pensamento complexo" ou teoria da complexidade e apreender com ele o que definiu ser sua maior obsessão: compreender a condição humana. Era essa dimensão que sentia necessidade de resgatar em meu espírito e em minha profissão.

E era essa dimensão que procurava quando fui realizar meus estudos pós-doutorais no Centre Transdisciplinaire em Paris, entre 1998 e 1999. Foi quando tive o privilégio de tê-lo como meu diretor de pesquisa. Na época, acabara de ler e reler Meus Demônios, publicação francesa de 1994, editado no Brasil em 1997. Neste livro, encontrara como que um eco de minhas próprias perplexidades e uma identificação de meus próprios "demônios". Edgar compreendeu e expressou sua compreensão na dedicatória ao meu exemplar deste livro: "para quem tem amizade por Meus Demônios, com minha amizade". É neste mesmo livro que escrevera:

[...] sentia-me sempre em oposição às ideias e aos costumes dominantes das categorias em que me encerravam [...] eu queria antes de tudo afirmar uma fidelidade a mim mesmo e às minhas ideias. [...] não mais queria me definir por oposição a outrem, queria me reconhecer em minhas ideias. (MORIN, 1997, p. 7). 
Demônios e possessões de ideias podem subverter nosso espírito, nosso cogito, nosso pensamento, nossa potência condutora de inteligência e de humanidade.

\section{Por alamedas}

Acordei cedo naquela manhã para tomar café com Edgar no Hotel Renaissanse. Caminhando por uma alameda da cidade, expunha com certa vibração a descoberta no Centre de um ensaio escrito por ele, chamado Marx is meet Sociologie, em que problematiza o significado e a ambivalência interna do marxismo entre um sistema ou uma doutrina, por um lado, e um método, por outro (cf. RODRIGUES; CARVALHO, 2004, p. 74). Entusiasmado com meu próprio entusiasmo, entre um café e um croissant, Edgar propôs que eu traduzisse para publicação e reunisse em um só livro, seus artigos sobre o marxismo, dispersos nas Revistas Arguments, nos Cahiers d'Études Socialistes, nos Chemins du Institut de Recherches Sociologiques et Anthropologiques e outros, resultados que eram de muitas tardes de reflexões que realizava com Claude Lefort, Pierre Naville, Cornelius Castoriadis, Costas Axelos, entre as décadas de 1950 e 1990. Enviaria todo o material para minha residência e eu poderia organizálo da maneira que julgasse melhor. Não preciso mencionar meu susto, surpreendida por inesperada incumbência que não sabia se seria capaz de realizar. De repente, via-me com a responsabilidade de trazer para o presente o que Edgar Morin conserva e o que nega, o que integra, critica ou relativiza do marxismo e, além disso, promover uma organização de textos que agrupasse reflexões sobre o assunto, inédita no contexto de suas produções (cf. RODRIGUES; CARVALHO, 2004, p. 9).

Foi um café especialíssimo, que não vou esquecer jamais! Ancorei-me em outra professora de excelência em francês para realizar a tradução, concluindo assim, no ano de 2002, a $1^{\text {a }}$ edição do livro Em busca dos fundamentos perdidos: textos sobre o marxismo, lançado pela editora Sulina. Oito anos depois, em 2010, o livro seria publicado em Paris pela editora Temps Présent, sob o título Pour et contre Marx (MORIN, 2010).

Devagar e a cada tempo, procuro encontrar-me com Edgar e continuar a acompanhá-lo, aprender com ele, cada vez mais aproximar-me de reflexões e atitudes que me permitam reconhecer o desafio da "condição humana em sua multidimensionalidade".

Para Morin, a reforma do nosso pensamento é ponto de partida para o início de outras transformações e o enfrentamento das mudanças. Poderíamos continuar refletindo sobre os caminhos por ele apontados para lidar com nossas próprias dificuldades, desencadeadas por tantas crises do nosso tempo, tais como a da mundialização, do cruel neoliberalismo, dos 
diferentes autoritarismos, das incompreensões éticas e políticas, das cegueiras que nos dominam, das possessividades diversas, da inveja e do ódio que envenenam nossas vidas, do poder que nos magnetiza, da degradação de nossa humanidade. Mas deixo aqui uma proposta e um convite. Porque também somos responsáveis pelas dores e sofrimentos sociais, façamos de nossa indignação um propósito positivo. Se Edgar, em seus 100 anos, continua com toda sua força e coragem confrontando-se com a hybris, porque não agirmos em direção à transformação do pensamento, na construção de uma nova Via, de uma nova Política de Civilização? Aquela civilização “[...] destinada a suprimir a barbárie das relações humanas: a exploração do homem pelo homem, o arbítrio dos poderes, o egocentrismo, o etnocentrismo, a crueldade, a incompreensão" (MORIN; NAIR, 1997, p. 149).

\section{Referências}

MORIN, E. Ciência com Consciência. Sintra, Portugal: Publicações Europa-América, 1994. (Col. Biblioteca Universitária, 32).

MORIN, E. Meus Demônios. Rio de Janeiro: Bertrand Brasil, 1997.

MORIN, E. Para Sair do Século XX. Rio de Janeiro: Nova Fronteira, 1986.

MORIN, E. Pour et Contre Marx. Paris: Édition Temps Présent, 2010. (Col. Racines \& Ruptures).

MORIN, E. X da Questão: O sujeito à flor da pele. Porto Alegre: Artmed, 2003.

MORIN, E. É hora de mudarmos de via - as lições do coronavírus. Rio de Janeiro: Bertrand Brasil, 2020.

MORIN, E.; NAIR, S. Uma Política de Civilização. Lisboa: Instituto Piaget, 1997.

MUCHAIL, S. T. Foucault, Mestre do Cuidado: textos sobre a hermenêutica do sujeito. São Paulo: Editora Loyola, 2011.

RODRIGUES, M. L.; CARVALHO, E. de A. (org.). Edgar Morin: Em Busca dos Fundamentos Perdidos - textos sobre o marxismo. Porto Alegre: Editora Sulina, 2004. 